\title{
Intrafamilial clinical variability of type 1 Gaucher disease in a French-Canadian family
}

\author{
F Y M CHOY
}

From the Department of Pediatrics and Center for Human Genetics, The McGill University-Montreal Children's Hospital Research Institute, Montreal, Quebec H3H 1P3, Canada.

SUMMARY Glucocerebroside $\beta$-glucosidase (glucocerebrosidase) activity was determined from peripheral blood lymphocytes and cultured skin fibroblasts of eight full sibs in a French-Canadian family at risk for Gaucher disease, an autosomal recessive sphingolipidosis resulting from deficient glucocerebrosidase activity. The diagnosis of type 1, non-neuronopathic Gaucher disease was made in all of the five affected sibs on the basis of deficient $(7 \cdot 5$ to $15 \cdot 5 \%$ of control mean) glucocerebrosidase activity and absence of neurological involvement. Normal levels of enzyme activity were found in two of the three asymptomatic sibs. The third asymptomatic sib had an intermediate level (about $50 \%$ of control mean) of fibroblast and lymphocyte glucocerebrosidase activity, indicating that he is a carrier. Considerable clinical heterogeneity was noted among the five affected sibs. One patient is mildly affected and so far has not developed any orthopaedic complications associated with Gaucher disease. His haematological complications were also reversed after splenectomy 24 years ago. In contrast to this mild presentation, the patient's splenectomised sister has been very anaemic and thrombocytopenic. There have been severe orthopaedic complications associated with Gaucher disease, including vertebral compression, avascular necrosis, and pathological fracture of the long bones. The clinical picture of the other three affected sibs appeared to vary between the two extremes. Although the asymptomatic parents of the patients died many years ago, their heterozygous status with respect to Gaucher disease can be deduced by the presence of Gaucher homozygotes, normal homozygotes, and one heterozygote among their eight offspring. Present findings suggest that the clinical variability of type 1 Gaucher disease may be attributed to variable expressions of the same Gaucher mutant alleles, in addition to the presence of multiple mutant alleles that are widely disseminated in the population.

Zlotogora et al $^{1}$ recently postulated a model to account for the clinical variability of type 1 (nonneuronopathic) Gaucher disease, an autosomal recessive sphingolipidosis resulting from deficient glucocerebroside $\beta$-glucosidase (glucocerebrosidase or glucosylceramidase, EC.3.2.1.45) activity. ${ }^{23}$ According to their modei, ${ }^{1}$ there are at least two different allelic mutations at the glucocerebrosidase locus $\left(G_{1}{ }^{a}\right.$ and $\left.G_{1}{ }^{b}\right)$, resulting in three different genotypes: $G_{1}{ }^{a} G_{1}{ }^{a}$ (severe form), $G_{1}{ }^{b} G_{1}{ }^{b}$ (moderate form), and $G_{1}{ }^{a} G_{1}{ }^{b}$ (mild form). ${ }^{1}$

The above model was used by these investigators to explain the intrafamilial similarity in clinical manifestation among affected sibs of heterozygous parents, and the intrafamilial variability among affected sibs of at least one affected parent. ${ }^{1}$

Received for publication 14 April 1987 Accepted for publication 20 May 1987.
However, they noted that a previous report from our laboratory on the intrafamilial clinical variability of Gaucher disease in a French-Canadian family appeared to be an exception to their model. They also commented ${ }^{1}$ that information on the parents of the affected sibs in this family was lacking, since the parents were not examined.

The purpose of this report is to provide additional clinical and biochemical findings on this FrenchCanadian family at risk of Gaucher disease. On the basis of these findings, it is suggested that other factors besides the Gaucher mutant alleles may also affect or modify the clinical manifestation of Gaucher disease.

\section{Case reports}

The pedigree of this family is shown in the figure. The genotype status of the family members with 


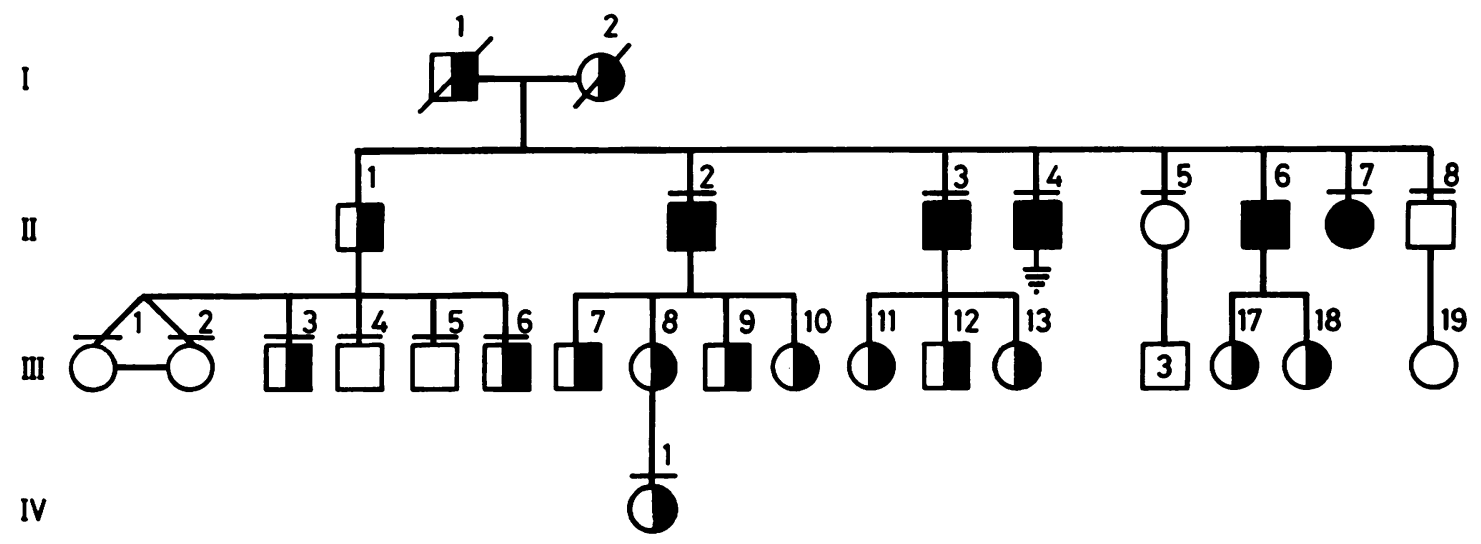

FIGURE Pedigree of the French-Canadian family with Gaucher disease.

respect to Gaucher disease was ascertained biochemically by determining glucocerebrosidase activity from cultured skin fibroblasts and peripheral blood lymphocytes. Among the eight full sibs in the second generation (II.1-8), five were diagnosed as having type 1, non-neuronopathic Gaucher disease on the basis of deficient glucocerebrosidase activity $(7.5$ to $15 \cdot 5 \%$ of normal mean) and absence of neurological involvement. ${ }^{5}$ Normal levels of fibroblast and lymphocyte glucocerebrosidase activity were found in two of the asymptomatic sibs ${ }^{5}$ (II.5 and II.8) and in the spouses of all seven sibs. The third asymptomatic sib (II.I) had an intermediate level of fibroblast and lymphocyte glucocerebrosidase activity $(52.9$ and $56.7 \%$ of normal mean ${ }^{5}$ ), indicating that he is a carrier. The genotypes of the offspring of II.1 and III.8 were ascertained biochemically by determining the level of lymphocyte glucocerebrosidase activity.
Considerable clinical heterogeneity was noted among the five affected sibs (II.2, 3, 4, 6, and 7). Patient II.6 is mildly affected and so far has not developed any orthopaedic complications associated with Gaucher disease (table). His haematological complications were also reversed after splenectomy 24 years ago. In contrast to this mild presentation, the clinical picture of his affected sister (II.7) appeared to be much more severe. Since the diagnosis of Gaucher disease at the age of 16 (table), she has been very anaemic and thrombocytopenic. There have been severe orthopaedic complications associated with Gaucher disease, including vertebral compression, arthritis, avascular necrosis, pathological fracture of the long bones, and total right hip arthroplasty (table). She is very prone to infection and remains debilitated. The clinical picture of the other three affected sibs (II.2, 3, and 4,) appeared to

TABLE Summary of patient data.

\begin{tabular}{|c|c|c|c|c|c|}
\hline Patient & $\begin{array}{l}\text { Present } \\
\text { age } \\
(1987)\end{array}$ & Sex & $\begin{array}{l}\text { Age at } \\
\text { diagnosis }\end{array}$ & $\begin{array}{l}\text { Age at } \\
\text { splenectomy }\end{array}$ & Bone disease \\
\hline II. 2 & 60 & $\mathbf{M}$ & 35 & 35 & $\begin{array}{l}\text { Intermittent pain in hips at age } 51 . \\
\text { osteonecrosis of femoral heads }\end{array}$ \\
\hline 11.3 & 59 & $\mathbf{M}$ & 33 & 33 & $\begin{array}{l}\text { Intermittent shoulder and hip pain at age } \\
43 \text {, osteonecrosis of humeral head. } \\
\text { arthritis. bilateral total hip arthroplasty }\end{array}$ \\
\hline II. 4 & 56 & $\mathbf{M}$ & 41 & 41 & $\begin{array}{l}\text { At age } 50 \text {, pain and swelling of both knees, } \\
\text { osteonecrosis of both medial femoral } \\
\text { condyles. advanced arthritis. Severe } \\
\text { involvement of whole femur }\end{array}$ \\
\hline II. 6 & 49 & $\mathbf{M}$ & 25 & 25 & $\begin{array}{l}\text { None, radiograph shows normal appearance of } \\
\text { hip. femoral heads, and shoulder joints }\end{array}$ \\
\hline II. 7 & 44 & $\mathrm{~F}$ & 16 & 19 & $\begin{array}{l}\text { Sustained vertebral compression fracture at } \\
\text { age } 16 \text { : at age } 31 \text {. increasing pain in right } \\
\text { hip. avascular necrosis of femoral head. } \\
\text { severe arthritis. total right hip } \\
\text { arthroplasty }\end{array}$ \\
\hline
\end{tabular}


be somewhere in between. There were moderate haematological complications and moderate to severe osseous manifestations (table).

Although the asymptomatic parents (I.1 and 2) died many years ago and therefore are not available for examination, their heterozygous or carrier status with respect to Gaucher disease can be deduced by the presence of Gaucher homozygotes (II.2, 3, 4, 6, and 7), Gaucher heterozygotes (II.1), as well as normal subjects (II.5 and 8) among their eight offspring. The presence of the two unaffected offspring with normal levels of glucocerebrosidase activity also eliminated the possibility that their parents were genetic compounds. Based on this finding, it appears that all of the affected sibs in the second generation (II.2, 3, 4, 6, and 7) had inherited the same Gaucher alleles from their Gaucher heterozygote parents.

Previous reports from our laboratory ${ }^{78}$ and from other investigators ${ }^{9} 10$ showed that there was no clear correlation between the level of residual glucocerebrosidase activity in fibroblasts and the clinical severity associated with the different Gaucher subtypes. These findings suggest that the in vitro enzyme assay condition may not reflect the complete in vivo conditions.

In attempting to account for the clinical variability of type 1 Gaucher disease, Zlotogora et al ${ }^{1}$ have proposed a model of multiple alleles. Since the Gaucher allele is frequent in some populations and is also widely disseminated among other populations, ${ }^{1}{ }^{3}$ multiple alleles undoubtedly contribute to the phenotypic variability seen among type 1 patients.

The family we have described also points to a variable expression of the same allele (or combination of alleles) as an additional source of this variability. The importance of the distinction between clinical variability owing to multiple alleles versus clinical variability owing to differential expression of the same alleles is that the latter phenomenon focuses attention on other (and possibly treatable) genetic or environmental factors which, if identified and controlled, could affect the clinical course of the disease. The identity of factors which contribute to the clinical outcome of Gaucher disease is, of course, not known at present but those processes which affect the level of glucocerebroside and its circulation within histiocytes may be candidates for investigation. Nilsson et $\mathbf{l}^{11}$ reported that the clinical severity of type 1 Gaucher disease appeared to be correlated to the level of glucocerebroside and its toxic derivative, glucosylsphingosine, in tissues of patients. In view of this finding and the fact that there is a profound deficiency of glucocerebrosidase activity in Gaucher disease, factors that affect endogeneous glucocerebroside production may play a crucial role in modifying the phenotypic expression in patients. Since erythrocyte membrane is considered to be one of the predominant sources of glucocerebroside in the body, ${ }^{3}$ such factors may include putative genes that regulate the rate of erythropoiesis and erythrocyte turnover, as well as the level of glucosylsphingosine and other toxic derivatives generated from stored glucocerebroside. Other factors that affect the blood circulation and migration of lipid laden histiocytes (Gaucher cells) to the bone marrow sinusoid may also contribute to the orthopaedic complications associated with Gaucher disease.

This study was supported by grants MA- 4632 and B42 from the Medical Research Council of Canada and the McGill University-Montreal Children's Hospital Research Institute to F Y M Choy. The author would like to thank Dr Peter Hechman for his most helpful suggestions and critical reading of the manuscript, Miss Mary Woo for her technical assistance, and Ms Carolyn Mandel for her clerical assistance. This is publication No 88001 of the McGill University-Montreal Children's Hospital Research Institute.

\section{References}

1 Zlotogora J, Zaigov R, Klibansky C, Matoth Y, Bach G, Cohen $\mathrm{T}$. Genetic heterogeneity in Gaucher disease. J Med Genet 1986;23:319-32.

2 Brady RO, Kanfer JN, Shapiro D. Metabolism of glucocerebrosidase II. Evidence of enzymatic deficiency in Gaucher's disease. Biochem Biophys Res Commun 1965;18:221-5.

3 Brady RO, Barranger JA. Glucosylceramide lipidosis: Gaucher disease. In: Stanbury JB, Wyngaarden JB, Fredrickson DS, Goldstein JL, Brown MS, eds. The metabolic basis of inherited disease. 5th ed. New York: McGraw-Hill, 1983:842-56.

${ }^{4}$ Choy F, Bouilon L. Heterogeneity of type 1 Gaucher disease in a French Canadian family. Am J Hum Genet 1982;34:83A.

5 Choy FYM. Gaucher disease: comparative study of acid phosphatase and glucocerebrosidase in normal and type 1 Gaucher tissues. Am J Med Genet 1985;21:519-28.

${ }^{6}$ Choy FYM, Bouillon L, Laurin CA. Gaucher disease: accurate identification of asymptomatic French-Canadian carrier using non-labelled authentic sphingolipid substrates $\mathrm{N}$-palmitoyl dihydroglucocerebroside. Am J Med Genet 1987;27:895-905.

${ }^{7}$ Choy FYM. Gaucher disease: the effect of phosphatidylserine on glucocerebrosidase from normal and Gaucher fibroblasts. Hum Genet 1984;67:432-6.

${ }^{8}$ Choy FYM, Woo M, Potier M. In situ radiation-inactivation size of fibroblast membrane-bound acid $\beta$-glucosidase in Gaucher type 1, type 2, and type 3 disease. Biochim Biophys Acta 1986;870:76-81.

9 Wenger DA, Olson GC. Heterogeneity in Gaucher disease. In: Callahen JW, Lowden JA, eds. Lysosomes and lysosomal storage diseases. New York: Raven Press, 1981:151-71.

10 Pentchev PG, Barranger JA, Gal AE, Furbish FS, Brady RO Incorporation of exogenous enzymes into lysosomes. A theoretical and practical means for correcting lysosomal blockage. In Walborg EF, ed. Glycoproteins and glycolipids in disease 
processes. Washington DC, American Chemical Society Symposium Series No 80, 1978:150.

" Nilsson O, Grabowsky GA, Ludman MD, Desnick RJ, Svennerholm L. Glycosphingolipid studies of visceral tissues and brain from type 1 Gaucher disease variants. Clin Genet 1985;27:443-50.
Correspondence and requests for reprints to Dr F Y M Choy, Department of Pediatrics, The McGill University-Montreal Children's Hospital Research Institute, 2300 Rue Tupper Street, Montreal, Quebec H3H 1P3, Canada. 